\title{
Protists Within Corals: The Hidden Diversity
}

\author{
Camille Clerissi ${ }^{1 *}$, Sébastien Brunet ${ }^{2}$, Jeremie Vidal-Dupiol ${ }^{3}$, Mehdi Adjeroud ${ }^{4}$, \\ Pierre Lepage ${ }^{2}$, Laure Guillou ${ }^{5}$, Jean-Michel Escoubas ${ }^{6}$ and Eve Toulza ${ }^{\text {1* }}$
}

${ }^{1}$ Univ. Perpignan Via Domitia, IHPE UMR 5244, CNRS, IFREMER, Univ. Montpellier, Perpignan, France, ${ }^{2}$ McGill University and Génome Québec Innovation Centre, Montréal, QC, Canada, ${ }^{3}$ IFREMER, IHPE UMR 5244, Univ. Perpignan Via Domitia, CNRS, Univ. Montpellier, Montpellier, France, ${ }^{4}$ Institut de Recherche pour le Développement, UMR 9220 ENTROPIE \& Laboratoire d'Excellence CORAIL, Université de Perpignan, Perpignan, France, ${ }^{5}$ CNRS, UMR 7144, Sorbonne Universités, Université Pierre et Marie Curie - Paris 6, Station Biologique de Roscoff, Roscoff, France, ${ }^{6}$ CNRS, IHPE UMR 5244, Univ. Perpignan Via Domitia, IFREMER, Univ. Montpellier, Montpellier, France

Previous observations suggested that microbial communities contribute to coral health and the ecological resilience of coral reefs. However, most studies of coral microbiology focused on prokaryotes and the endosymbiotic algae Symbiodinium. In contrast, knowledge concerning diversity of other protists is still lacking, possibly due to methodological constraints. As most eukaryotic DNA in coral samples was derived from hosts, protist diversity was missed in metagenome analyses. To tackle this issue, we designed blocking primers for Scleractinia sequences amplified with two primer sets that targeted variable loops of the 18S rRNA gene (18SV1V2 and 18SV4). These blocking primers were used on environmental colonies of Pocillopora damicornis sensu lato from two regions with contrasting thermal regimes (Djibouti and New Caledonia). In addition to Symbiodinium clades A/C/D, Licnophora and unidentified coccidia genera were found in many samples. In particular, coccidian sequences formed a robust monophyletic clade with other protists identified in Agaricia, Favia, Montastraea, Mycetophyllia, Porites, and Siderastrea coral colonies. Moreover, Licnophora and coccidians had different distributions between the two geographic regions. A similar pattern was observed between Symbiodinium clades $C$ and A/D. Although we were unable to identify factors responsible for this pattern, nor were we able to confirm that these taxa were closely associated with corals, we believe that these primer sets and the associated blocking primers offer new possibilities to describe the hidden diversity of protists within different coral species.

Keywords: holobiont, protists, symbiosis, metabarcoding, blocking primer, Scleractinia, Pocillopora damicornis

\section{INTRODUCTION}

Scleractinian corals build reefs all around the world. The ecological success of corals in the oligotrophic seawater of coral reefs mostly relies on the symbiosis with dinoflagellates (genus Symbiodinium). In particular, the symbiosis between corals and Symbiodinium takes place within coral cells, where the algal symbionts provide organic compounds to corals through their photosynthetic activity, and in turn receive nutrients and metabolic compounds from their host. Symbiodinium is a diverse genus divided into nine clades (Coffroth and Santos, 2005; Pochon et al., 2006; Quigley et al., 2014; Thornhill et al., 2017). Among these clades, five have been identified in coral cells (clades A, B, C, D, and F). 
Corals are also associated with a high diversity of microorganisms (bacteria, archaea, fungi, endolithic algae, protozoa, and viruses) (Rohwer et al., 2002; Wegley et al., 2004; Thurber et al., 2017), and the complex formed by coral and the associated microorganisms corresponds to a single entity called the holobiont (Rohwer et al., 2002; Theis et al., 2016). Among them, the bacterial genus Endozoicomonas was found in high abundances within many coral species (Bayer et al., 2013; Neave et al., 2016, 2017). This genus was thought to be a beneficial symbiont to corals. Moreover, rare bacterial taxa (genera Ralstonia and Propionibacterium) were ubiquitous as well (Ainsworth et al., 2015). In addition to Symbiodinium, other unicellular eukaryotes (protists) were found to live with corals, including many Stramenopiles (Kramarsky-Winter et al., 2006; Harel et al., 2008; Siboni et al., 2010), several apicomplexans such as Chromera and coccidians (Toller et al., 2002; Moore et al., 2008; Janouškovec et al., 2012; Kirk et al., 2013; Mohamed et al., 2018), different fungi (Amend et al., 2012), and different boring microflora (e.g., Ostreobium, Phaeophila, and Porphyra) (Tribollet, 2008b; Pica et al., 2016).

Unlike for Symbiodinium, the role of these microorganisms remains unknown within the holobiont. First, they might provide protection against pathogens through the secretion of antimicrobial compounds (Ritchie, 2006; Shnit-Orland and Kushmaro, 2009). Secondly, in addition to Symbiodinium, they might also provide metabolic compounds to corals (KramarskyWinter et al., 2006; Harel et al., 2008; Siboni et al., 2010). Thirdly, microbial communities might play an important role for coral heat tolerance (Ziegler et al., 2017), and for the ecological resilience of coral reefs (McDevitt-Irwin et al., 2017). As a consequence, these observations suggested that microbial communities contribute to coral health and homeostasis, through the presence of Beneficial Microorganisms for Corals (BMC) (Peixoto et al., 2017).
To date, however, most studies have focused on Symbiodinium and coral-associated bacteria. In particular, very little is known concerning the diversity and the role of other protists (Ainsworth et al., 2017), though several studies have shown that they play an important role in the structure and function of marine ecosystems (Thingstad et al., 2008; de Vargas et al., 2015). Previous analyses of protists mainly used non-destructive sampling techniques (microscope, culture) or low-throughput methods for environmental DNA (qPCR, cloning), though these methods were less effective at detecting diversity when compared to mass sequencing of the $18 \mathrm{~S}$ rRNA gene for example. Because most DNA in coral samples was extracted from the host and the $18 \mathrm{~S}$ rRNA gene is shared between corals and protists, to date high-throughput studies of protist diversity have been a challenge (Šlapeta and Linares, 2013).

To tackle this issue, we designed blocking primers for Scleractinia sequences in order to decrease their proportions relative to protist sequences. Such an approach was already effective in the study of fish and krill gut contents (Vestheim and Jarman, 2008; Leray et al., 2013), and in the removal of metazoa sequences from seawater community samples (Tan and Liu, 2018). To the best of our knowledge, this is the first time that this strategy has been used on coral samples. These blocking primers targeted regions similar to the reverse primer for each of the two primer sets used to amplify variable loops of the 18S rRNA gene (V1V2 and V4) (Wuyts et al., 2000, 2002; Stoeck et al., 2010).

Both blocking primers were used to explore protist diversity within colonies of $P$. damicornis sensu lato that were sampled from two geographic regions with contrasting thermal regimes: Djibouti and New Caledonia (Figure 1 and Supplementary Table 1). A previous study on these samples showed different Symbiodinium clades between these regions using ITS2 (internal transcribed spacer 2) (Brener-Raffalli et al., 2018). These authors also highlighted that colonies from Djibouti and New Caledonia

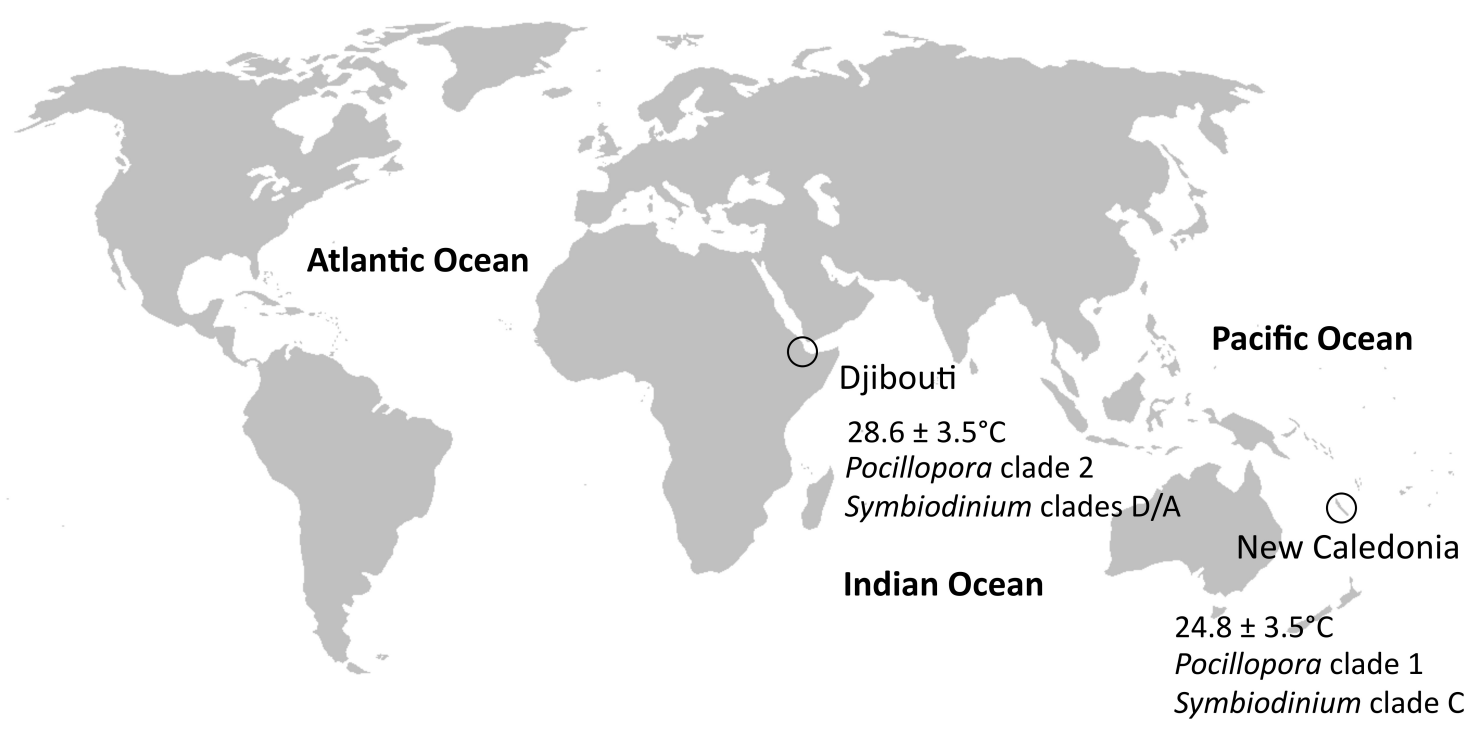

FIGURE 1 | Sampling sites. Djibouti and New Caledonia had different thermal regimes and clades of P. damicornis and Symbiodinium. 
corresponded to two different clades of $P$. damicornis. As a consequence, geography, genetics and environmental conditions divided the two $P$. damicornis populations, and allowed for the comparison of different holobionts.

\section{MATERIALS AND METHODS}

\section{Sampling Sites}

Colonies of $P$. damicornis sensu lato growing between one to five meters depth were sampled by snorkeling within two regions (Djibouti and New Caledonia) in six localities (Figure 1 and Supplementary Table 1). A total of 16 colonies were sampled during this survey. The tip $(1-2 \mathrm{~cm})$ from one healthy branch of each colony was cut and placed individually in a plastic bag. Each bag was filled with seawater surrounding the colony to hold samples during the sampling cruise. Samples were subsequently transferred into modified CHAOS buffer (4 $\mathrm{M}$ guanidium thiocyanate, $0.5 \% \mathrm{~N}$-lauryl sarcosine sodium $25 \mathrm{mM}$ Tris- $\mathrm{HCl} \mathrm{pH}$ 8, $0.1 \mathrm{M} \beta$-Mercaptoethanol) as previously described (Adjeroud et al., 2014).

\section{Design of Blocking Primers for Scleractinia}

A preliminary sequencing test was performed to study eukaryote diversity within a sample of $P$. damicornis using two primer sets targeting two differents regions of the 18S rRNA gene, 18SV1V2 and 18SV4 (Table 1). While primers for 18SV4 were designed previously to amplify all eukaryotic-specific $18 \mathrm{~S}$ rDNA (Stoeck et al., 2010), primers for 18SV1V2 were designed using the Protist Ribosomal Reference database ( $\mathrm{PR}^{2}$ ) (Guillou et al., 2012) in order to prevent amplification of metazoan 18S rRNA genes especially from Crassostrea gigas oysters. Both sequencing tests showed an excess of amplicons from $P$. damicornis, since they represented $\sim 99 \%$ of sequences (for a total of 3383 and 2460 cleaned sequences using $18 \mathrm{SV} 1 \mathrm{~V} 2$ and $18 \mathrm{SV} 4$, respectively; data not shown).

Thus we designed blocking primers for both primer sets in order to reduce the proportion of $P$. damicornis amplicons. First, we downloaded the non-redundant (99\%) Silva SSU database (release 128, September 2016) (Quast et al., 2013; Yilmaz et al., 2014). Then we only kept sequences that matched with either the primer set for 18SV1V2 or 18SV4. Based on annotations, metazoa were removed to produce a metazoa-free database and sequences of Scleractinia were used to create a host database. In order to design blocking primers that overlap the reverse primer and the $3^{\prime}$-region of Scleractinia amplicons, we aligned the last 40 nucleotides (corresponding to the $3^{\prime}$-region of amplicon and the reverse primer) of Scleractinia with metazoafree database using MUSCLE v3.8.31 (Edgar, 2004). Then, we analyzed the nucleotide polymorphism at each position of the alignment for Scleractinia and metazoa-free sequences using entropy decomposition ( $\mathrm{R}$ package \{otu2ot\}, CalcEntropy.seq) (Ramette and Buttigieg, 2014). According to previous studies and entropy values (Supplementary Figure 1), we designed blocking primers $<30 \mathrm{bp}$ with $10 \mathrm{bp}$ overlapping the reverse primer, and having a Tm similar to the targeted primer set (Vestheim and Jarman, 2008; Leray et al., 2013). The best candidate for each primer set (targeting either 18SV1V2 or 18SV4 region) was identified using specificity tests against the Scleractinia and metazoa-free databases. Lastly, these primers were synthesized and modified at the $3^{\prime}$-end with a Spacer C3 CPG (3 hydrocarbons).

\section{DNA Extraction, PCR, and Sequencing}

DNA extractions were performed using CTAB (Cetyl TrimethylAmmonium Bromide)-based extraction method (Winnepenninckx et al., 1993). Briefly, coral tips were lysed $2 \mathrm{~h}$ in $600 \mu \mathrm{L}$ CTAB buffer (2\% CTAB, $0.2 \% \beta$-Mercaptoethanol, $1.4 \mathrm{M} \mathrm{NaCI}, 20 \mathrm{mM}$ EDTA pH 8, $100 \mathrm{mM}$ Tris- $\mathrm{HCl} \mathrm{pH} \mathrm{8,}$ $100 \mu \mathrm{g} / \mathrm{mL}$ proteinase $\mathrm{K})$ at $60^{\circ} \mathrm{C}$. Thus protists of the whole coral tissues were analyzed in this study. An equal volume of chloroform:isoamyl-alcohol (24:1) was then added. After centrifugation for $10 \mathrm{~min}$ at $14,000 \mathrm{~g}$, the aqueous phase was transferred to a new tube and DNA was precipitated by adding $400 \mu \mathrm{L}$ of ice-cold isopropanol and incubating $1 \mathrm{~h}$ at $-20^{\circ} \mathrm{C}$. After centrifugation for $15 \mathrm{~min}$ at $14,000 \mathrm{~g}$, the supernatant was discarded and the pellet washed with $70 \%$ ethanol. The pellet was air-dried for $5 \mathrm{~min}$ and resuspended in water. DNA concentration and quality were checked with Epoch microplate spectrophotometer (BioTek Instruments, Inc.).

Then, the 18S rRNA gene of eukaryotic communities was amplified and sequenced using the variable V1V2 and V4 loops (Table 1; Wuyts et al., 2002; Stoeck et al., 2010). PCR reactions were carried in a $25 \mu \mathrm{l}$ volume with final concentrations of $0.4 \mu \mathrm{M}$ of each PCR primers, $0.02 \mathrm{U}$ of the Qiagen HotStar Taq DNA Polymerase, $0.2 \mathrm{mM}$ of the dNTP mix and $1 \times$ Taq buffer. In order to reduce amplification of $P$. damicornis amplicons, blocking primers were added to the PCR mix at a final concentration of $1.2 \mu \mathrm{M}$ (Table 1). PCR cycling included an initial incubation of $15 \mathrm{~min}$ at $96^{\circ} \mathrm{C}$ followed by 35 cycles of $96^{\circ} \mathrm{C}$ for $30 \mathrm{~s}, 52^{\circ} \mathrm{C}$ for $30 \mathrm{~s}$, and $72^{\circ} \mathrm{C}$ for $1 \mathrm{~min}$, with a final $10 \mathrm{~min}$ incubation at $72^{\circ} \mathrm{C}$. Paired-end sequencing (250 bp read length) was performed at the McGill University (Génome Québec Innovation Centre, Montréal, QC, Canada) on the MiSeq system (Illumina) using the v2 chemistry according to the manufacturer's

TABLE 1 | Primers and blocking primers used in this study.

\begin{tabular}{lll}
\hline Marker region & $\mathbf{1 8 S V 1 V 2}$ & $\mathbf{1 8 S V 4}$ \\
\hline Forward $\left(5^{\prime}->3^{\prime}\right)$ & ACCTGGTTGATCCTGCCA & CCAGCASCYGCGGTAATTCC \\
Reverse $\left(5^{\prime}->3^{\prime}\right)$ & GTARKCCWMTAYMYTACC & ACTTCGTTCTTGATYRA \\
Blocking primer $\left(5^{\prime}->3^{\prime}\right)$ & CTACCTTACCATCGACAGTTGATAG & TCTTGATTAATGAAAACATTCTTGGC \\
Expected amplicon size $(\mathrm{bp})$ & $\sim 340$ & $\sim 430$
\end{tabular}


protocol. Raw sequence data are available in the Sequence Read Archive repository under accession ID PRJNA393088 (to be released upon publication).

\section{Sequence Analyses}

The FROGS pipeline (Find Rapidly OTU with Galaxy Solution) implemented into a galaxy instance was used to define Operational Taxonomic Units (OTU), and compute taxonomic annotations (Escudié et al., 2017). Briefly, paired reads were merged using FLASH (Magoc and Salzberg, 2011). After denoising and primer/adapters removal with cutadapt (Martin, 2011), de novo clustering was done using SWARM that uses a local clustering threshold, with aggregation distance $d=3$ (Mahé et al., 2015). Chimera was removed using VSEARCH (Rognes et al., 2016). We filtered the dataset for singletons and performed affiliation using Blast+ against the Protist Ribosomal Reference database $\left(\mathrm{PR}^{2}\right)$ (Guillou et al., 2012) to produce an OTU and affiliation table in standard BIOM format. Because we were interested in studying low frequency OTUs, we used additional steps to remove most PCR and sequencing errors. First, we removed OTUs having an annotation with a blast coverage $<90 \%$. Secondly, we computed a phylogenetic tree of the whole OTUs using MAFFT (Katoh et al., 2002) and FastTree (GTR model) (Price et al., 2010). OTUs were removed from the dataset if they corresponded to very long branches on the phylogenetic tree (according to minimal branch length values). Lastly, OTUs were considered present in each sample if they had at least three sequences.

Rarefaction curves of protist species richness were produced using the \{phyloseq\} R package, and the rarefy_even_depth and ggrare functions (McMurdie and Holmes, 2013). We also used phyloseq to obtain abundances at the genus taxonomic rank (tax_glom function). Pielou's measure of evenness was computed using affiliated genera and the $\{$ vegan $\} \mathrm{R}$ package.

\section{Annotation of Symbiodinium OTUs}

In order to characterize the environmental diversity of Symbiodinium, reference sequences of Symbiodinium (clades A, B, C, D, and G) were obtained for each $18 \mathrm{~S}$ rRNA regions from the National Center for Biotechnology Information (NCBI) (Supplementary Table 2). In addition, we selected two outgroups: Polarella glacialis and Pelagodinium beii. The reference were aligned with the environmental sequences of Symbiodinium using MUSCLE v3.8.31 (Edgar, 2004), alignments were trimmed at each extremity, and sequences were clustered at different nucleotide similarities (from 90 to 99\%) using Mothur (Schloss et al., 2009). The environmental sequences were annotated for a similarity of 95 and $97 \%$ for 18 SV 1 V 2 and 18SV4, respectively, i.e., when all the reference sequences of Symbiodinium clade A, B, C, D, and G clustered into five different groups.

\section{Alignment and Phylogenetic Analyses}

In one hand, phylogenetic reconstructions of Symbiodinium reference isolates were carried out to compare phylogenetic signals of both 18SV1V2 and 18SV4 markers with ITS2. We selected two reference sequences of Symbiodinium clade A, three reference sequences of clade $B$, two reference sequences of clade $C$, one reference sequences of clade D and clade $G$ (Supplementary Table 3). Except the strain of clade G, sequences of the three markers were available for each reference isolate of Symbiodinium. For each marker, sequences were aligned using MUSCLE v3.8.31 (Edgar, 2004).

On the other hand, phylogenetic reconstructions were computed to describe either environmental Symbiodinium diversity, the whole protist genera or coccidians associated with P. damicornis samples. First, Symbiodinium diversity was studied according to the annotation step of Symbiodinium OTUs. In particular, we used the output alignment of Mothur obtained at 95 and 97\% similarity cutoffs for 18SV1V2 and 18SV4, respectively. These alignments contained representative OTUs of environmental Symbiodinium, the two outgroups (P. glacialis and $P$. beii), and the reference sequences of Symbiodinium clades. Secondly, sequences of protist genera, Symbiodinium clades, and P. damicornis (accession number: LT631138.1 for both 18SV1V2 and 18SV4) were aligned using MUSCLE v3.8.31 (Edgar, 2004). Thirdly, we described the diversity of coral-associated coccidians using reference sequences of Apicomplexa (Schrével et al., 2016), and best BLASTn hits of coccidian sequences of this study against the National Center for Biotechnology Information (NCBI).

Finally, all alignments were trimmed at each extremity and maximum likelihood (ML) trees were computed with IQTREE v1.3.8 using the best model (selected with the Bayesian information criterion) (Nguyen et al., 2015), and validated via a ultrafast bootstrap procedure with 1000 replicates (Minh et al., 2013).

\section{Statistical Analyses}

All statistical analyses were done using R v3.3.1 (R Core Team, 2008).

First, phylogenetic signals were compared between ITS2, 18SV1V2 and 18SV4 using Symbiodinium reference isolates. Patristic distances were obtained from phylogenetic trees ( $R$ package \{stats\}, cophenetic), and compared using Mantel test ( $\mathrm{R}$ package \{vegan\}, mantel) (Mantel, 1967).

Secondly, Fisher's exact tests (R package \{stats\}, fisher.test) were computed to estimate the association between protist genera and Symbiodinium clades with both geographic regions, i.e., Djibouti and New Caledonia.

$P$-values were adjusted for multiple comparisons using the Bonferroni correction (\{stats\}, p.adjust). The threshold of significance level was set at 0.05 .

\section{RESULTS}

\section{Specificity of Blocking Primers}

In order to describe protist diversity associated with P. damicornis colonies from Djibouti and New Caledonia, we performed a preliminary sequencing test using one sample and two primer sets targeting different variable loops of the 18S rRNA gene (V1V2 and V4). Since most sequences corresponded to $P$. damicornis, we designed blocking primers using the Silva SSU database (see 
TABLE 2 | In silico specificity of blocking primers.

\begin{tabular}{lcc}
\hline Removed taxa & 18SV1V2 (\%) & 18SV4 (\%) \\
\hline Scleractinia & 100 & 93.8 \\
Rhizaria & 1.6 & 0 \\
Nucletmycea & 0.4 & $<0.1$ \\
Alveolata & 0.1 & 0.6 \\
Cryptomonadales & 0 & 0.5 \\
Chloroplastida & 0 & 0.3 \\
\hline
\end{tabular}

Methods for more details). These blocking primers targeted $10 \mathrm{bp}$ of reverse primers and $\sim 15$ bp of the amplicon $3^{\prime}$ end of Scleractinia (Table 1 and Supplementary Figure 1). Because their $3^{\prime}$-end had a spacer C3 CPG, elongation is expected to abort, whereas annealing properties are not modified (Vestheim and Jarman, 2008). To estimate the specificity of these blocking primers, we identified sequences of the Silva database that matched with primer sets and blocking primers. We found a very high in silico specificity, since 100 and 93.8\% of Scleractinia were removed by the 18SV1V2 and 18SV4 blocking primers, respectively (Table 2). In addition, they removed very low fractions of protists found in the Silva database.

As a consequence, we used both primer sets and their blocking primers to study protists associated with the colonies of $P$. damicornis from Djibouti and New Caledonia. Because DNA extraction was done directly on coral tips, we expected to be able to describe the entire protist community (i.e., microbes that were part of the holobiont, and possibly environmental microbes). On average, each sample had $\sim 29,566$ Pocillopora sequences and $\sim 18,724$ protist sequences representing $\sim 26$ OTUs (Table 3 and Supplementary Table 4). While in silico analyses showed very high specificity of both blocking primers, PCR and MiSeq sequencing displayed higher host contamination (Figure 2A). Indeed, Pocillopora sequences still represented 71 and $48 \%$ of amplicons for 18SV1V2 and 18SV4, respectively. In particular, Pocillopora proportion was lower for 18SV4 than for 18SV1V2.

\section{Symbiodinium Diversity}

Rarefaction curves for protists tended to level off for both marker regions, suggesting that most diversity was sequenced in each sample (Supplementary Figure 2).

Not surprisingly, Symbiodinium accounted for most protist diversity within $P$. damicornis tissues for both primer sets (Figure 2B). In order to describe Symbiodinium diversity, we first estimated phylogenetic signals of both 18SV1V2 and 18SV4 compared to ITS2. ITS2 is the most common marker used to study Symbiodinium diversity (LaJeunesse et al., 2010; Wicks et al., 2010; Silverstein et al., 2011; Putnam et al., 2012; Tonk et al., 2013), since it has high polymorphism. The strength of correlation between the three markers was estimated using Mantel tests (Table 4). The three phylogenetic trees were significantly congruent (Supplementary Figure 3) $(p=0.003)$, but congruency with ITS2 was higher for 18 SV1V2 $(r=0.88)$ than for 18SV4 $(r=0.72)$ (Table 4). We then annotated environmental Symbiodinium OTUs using a clustering approach and reference sequences of Symbiodinium clade A, B, C, D, and G (Supplementary Table 4). We also computed phylogenetic reconstruction with $P$. glacialis and $P$. beii as outgroups (Figure 3). While Symbiodinium clades A, C and $D$ were common for both marker genes, strains from clade $G$ were not identified with 18SV1V2 nor with 18SV4. Moreover, Symbiodinium clade B was found with 18SV4 but not with $18 \mathrm{SV} 1 \mathrm{~V} 2$, and we were not able to assign all environmental

TABLE 3 | Number of sequences and OTUs.

\begin{tabular}{lcccc}
\hline Sample & $\begin{array}{c}\text { Total number } \\
\text { of raw } \\
\text { sequences }\end{array}$ & $\begin{array}{c}\text { Total number of } \\
\text { cleaned } \\
\text { sequences }\end{array}$ & $\begin{array}{c}\text { Total number } \\
\text { of OTUs }\end{array}$ & $\begin{array}{c}\text { Number of } \\
\text { Pocillopora } \\
\text { sequences }\end{array}$ \\
pequences \\
sefist
\end{tabular}

Values correspond to 18SV1V2/18SV4. 
A

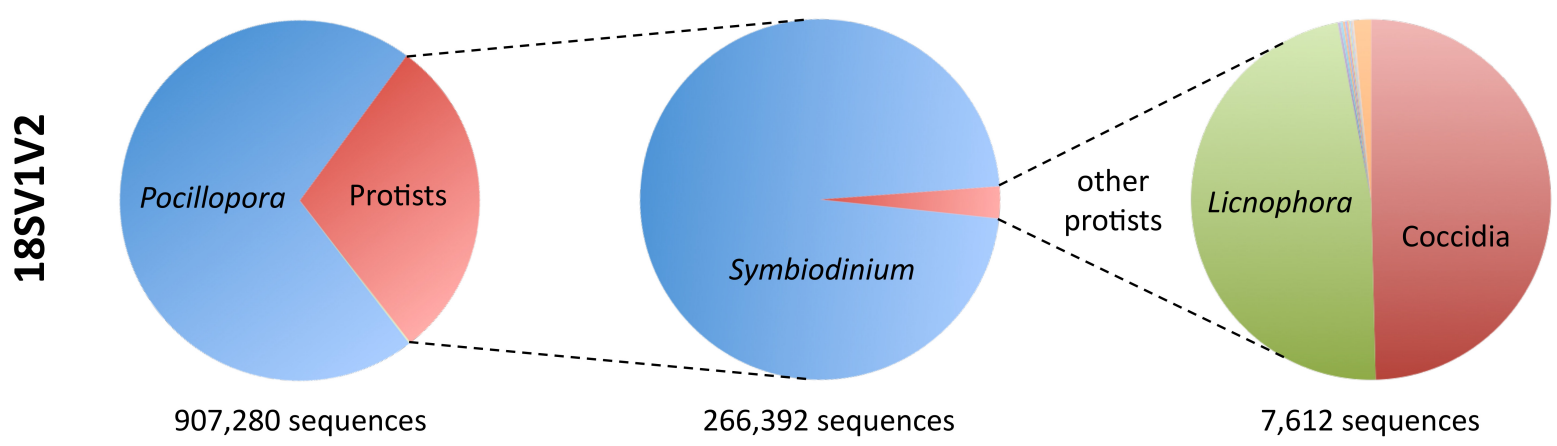

907,280 sequences

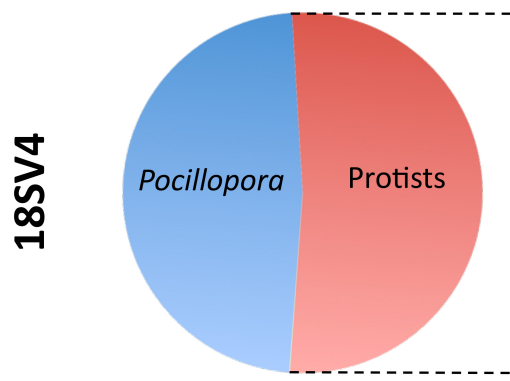

638,922 sequences
B

7,612 sequences

C

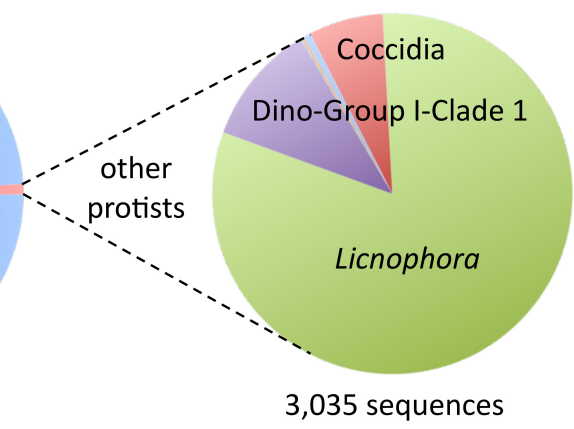

FIGURE 2 | Sequences of Pocillopora, Symbiodinium and the other protists for both marker regions. (A) Fraction of Pocillopora compared to protists. (B) Fraction of Symbiodinium compared to other protists. (C) Fraction of the other protists.

TABLE 4 | Phylogenetic congruences between ITS2, 18SV1V2, and 18SV4 markers for Symbiodinium.

\begin{tabular}{lccc}
\hline Marker 1 & Marker 2 & Correlation coefficient $(\mathbf{r})$ & $\boldsymbol{p}$-value \\
\hline ITS2 & 18SV1V2 & 0.88 & 0.003 \\
ITS2 & 18SV4 & 0.72 & 0.003 \\
18SV1V2 & 18SV4 & 0.83 & 0.003
\end{tabular}

Values correspond to correlation coefficients between patristic distances obtained using reference sequences of Symbiodinium and the Mantel test.

Symbiodinium to a known clade for $18 \mathrm{SV} 4$ in comparison to 18SV1V2 (Supplementary Table 4).

\section{Diversity of the Other Dominant Genera}

Although protist proportion was lower for 18SV1V2 (Figure 2A), the proportion of protists other than Symbiodinium was lower for $18 \mathrm{SV} 4$ (0.9\% compared to $2.9 \%$ for $18 \mathrm{SV} 1 \mathrm{~V} 2)$ (Figure 2B). The Symbiodinium genus was removed from the dataset to study the other protist genera of $P$. damicornis (Figure $2 \mathrm{C}$ and Supplementary Table 5). Licnophora, unidentified coccidians and Dino-Group I-Clade 1 (Syndiniales) were the main taxa found in $P$. damicornis samples among the 17 genera found with both primer sets. Among them, Licnophora represented a high fraction for 18SV1V2 and 18SV4, whereas coccidians showed different proportions between these markers. In particular,
18SV1V2 showed a more even protist diversity at the genus level than 18SV4 (0.05 > 0.03, Pielou's measure of evenness). A BLASTn search against NCBI nucleotide collection suggested that for both markers, Licnophora sequences were related to Licnophora strains, and that Dino-Group I-Clade 1 (Syndiniales) were similar to uncultured eukaryotes (Table 5). Interestingly, coccidian sequences were similar to protists already described in healthy coral colonies of Agaricia agaricita, A. tenuifolia, Favia fragum, Montastraea annularis, $M$. faveolata, Mycetophyllia ferox, Porites astreoides, and Siderastrea siderea (Toller et al., 2002; Kirk et al., 2013; Šlapeta and Linares, 2013). As a consequence, we computed a phylogenetic reconstruction of coral-associated coccidians with other Apicomplexa genera to describe their diversity. We found that all coral-associated coccidians formed a robust monophyletic clade (Figure 4). In addition, a phylogenetic tree using the longest available sequences of these symbionts highlighted their relationships with other marine Apicomplexa (Supplementary Figure 4), and confirmed that they corresponded to coccidians (Schrével et al., 2016).

\section{Distribution of $P$. damicornis-Associated Protists}

Because 18SV4 had (i) a low number of sequences related to protists other than Symbiodinium, (ii) low evenness for protist 

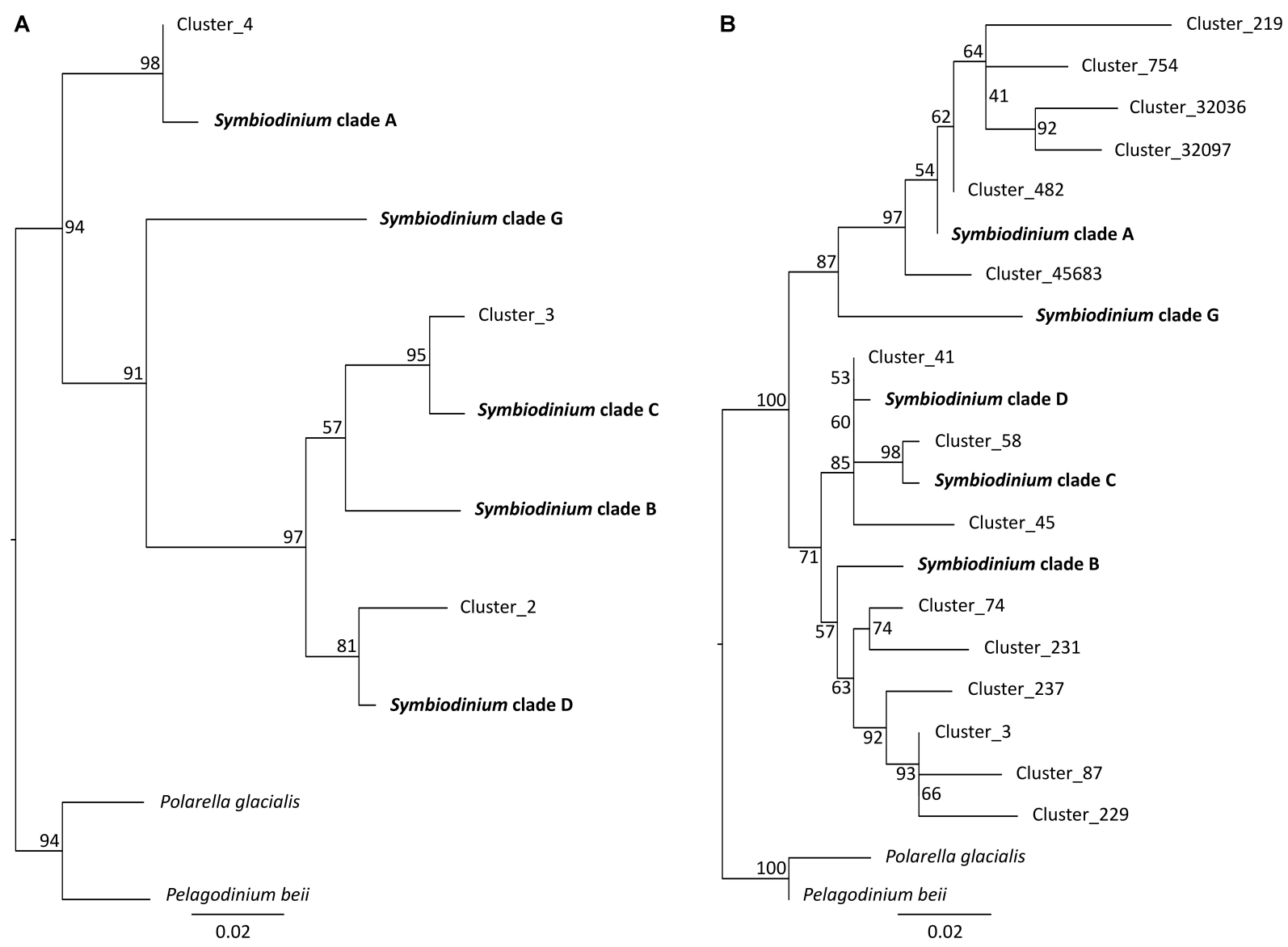

FIGURE 3 | Phylogenetic analyses of environmental and reference sequences of Symbiodinium. (A) 18SV1V2 sequences. (B) 18SV4 sequences. Only representative sequences of environmental Symbiodinium were used for these trees. Representative sequences were identified using a clustering method, and a nucleotide identity of 95 and 97\% for 18SV1V2 and 18SV4, respectively. The trees were rooted using two outgroups, Polarella glacialis and Pelagodinium beii. Numbers are bootstraps (\%) reflecting clade support.

TABLE 5 | BLASTn search of coccidians, Licnophora, and Dino-Group I-Clade 1 (Syndiniales) against NCBI.

\begin{tabular}{|c|c|c|c|c|c|c|}
\hline Marker region & Genus & Description & Identity (\%) & Coverage (\%) & $E$-value & Accession number \\
\hline 18SV1V2 & Dino-Group I-Clade 1 & $\begin{array}{l}\text { Uncultured eukaryote } \\
\text { clone SGYP555 }\end{array}$ & 100 & 100 & $6 e-152$ & KJ763756.1 \\
\hline \multirow[t]{3}{*}{$18 S V 4$} & Unidentified coccidia & $\begin{array}{l}\text { Coral symbiont from } \\
\text { Montastraea faveolata } \\
\text { haplotype } 12\end{array}$ & 99 & 100 & 0.0 & JX943876.1 \\
\hline & Licnophora & Licnophora macfarlandi & 96 & 100 & $2 e-165$ & AF527758.1 \\
\hline & Dino-Group I-Clade 1 & $\begin{array}{l}\text { Uncultured eukaryote } \\
\text { clone ST5900.009 }\end{array}$ & 100 & 100 & 0.0 & KF129971.1 \\
\hline
\end{tabular}

genera, and (iii) low phylogenetic signals (low congruency with ITS2 tree and low efficiency of annotations with reference Symbiodinium clades), we used 18SV1V2 amplicons to study protist distribution within the samples from Djibouti and New Caledonia.

A phylogenetic reconstruction of identified Symbiodinium clades and protist genera was carried out using maximum likelihood, and corresponding frequencies in samples were plotted in front of taxa (Figure 5). Two colors were used for frequencies to discriminate the high proportions of Symbiodinium, and lower values of other protists. Most protist genera were found in only one sample (e.g., Codonellopsis, Zoothamnopsis, Acineta, etc.). However, the different Symbiodinium clades, Licnophora and coccidians 


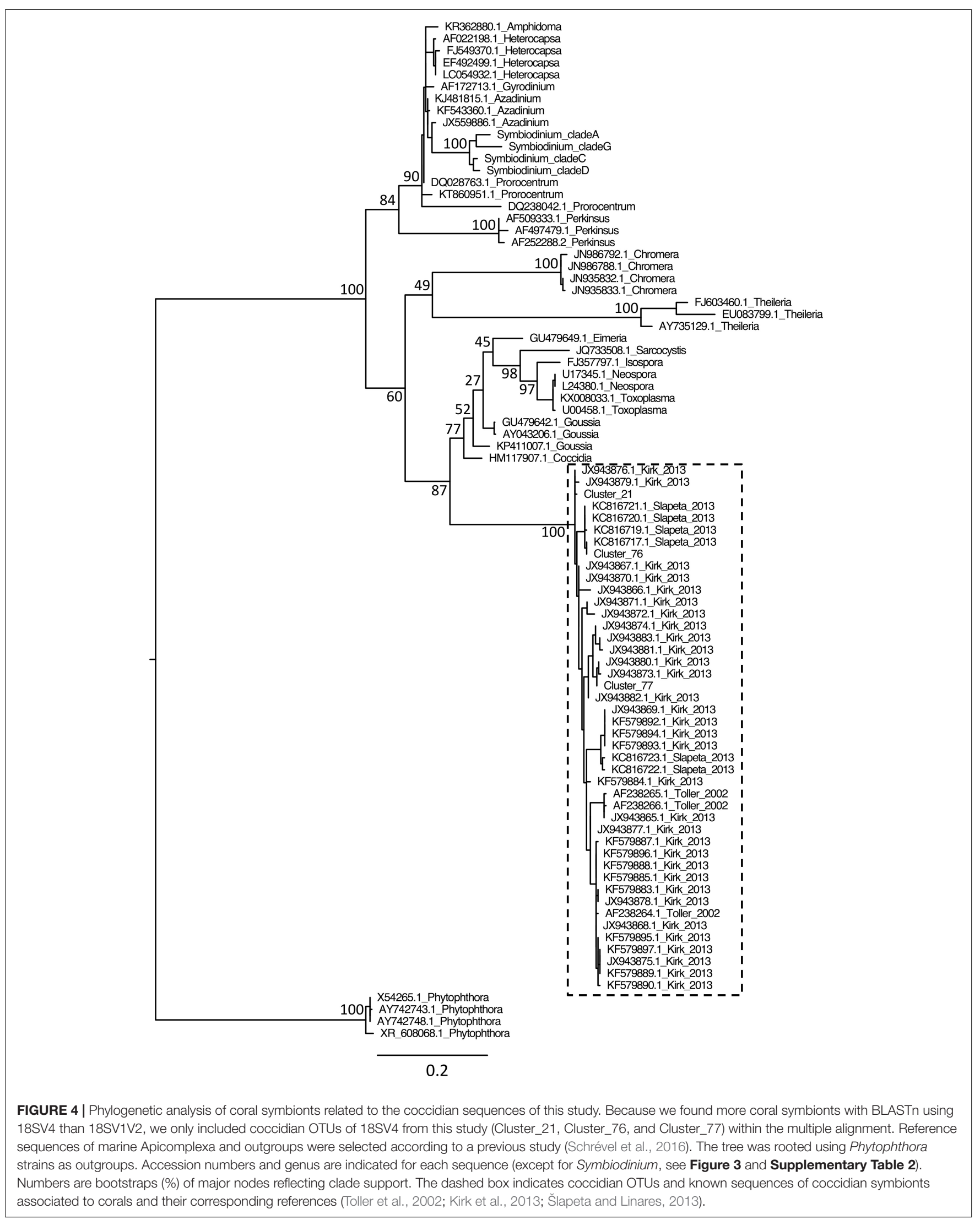




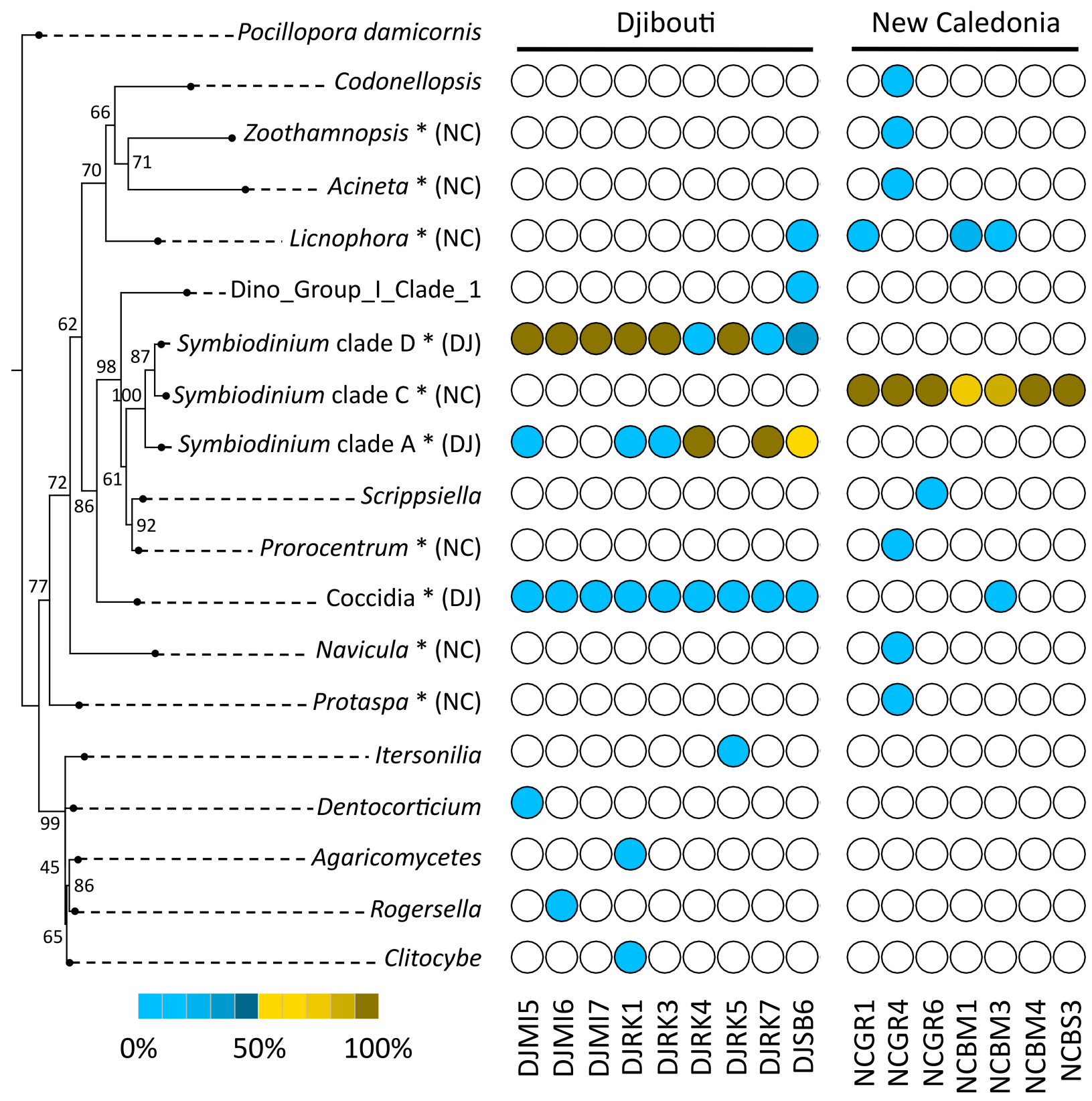

FIGURE 5 | Phylogenetic diversity and distribution of $P$. damicornis-associated protists using $18 \mathrm{SV} 1 \mathrm{~V} 2$ marker region. The tree was rooted using $P$. damicornis as outgroup. Numbers are bootstraps (\%) reflecting clade support. White circles indicate absence of taxa in samples. Brown circles indicate taxa frequency above 0.5 . Blue circles indicate taxa frequency below 0.5 . The gradient from light to dark colors indicates low to high frequencies of protists in each sample. *indicates significant taxa associated to Djibouti (DJ) or New Caledonia (NC) based on Fisher's exact test.

were present in several $P$. damicornis colonies. In particular, we observed different distribution between Djibouti and New Caledonia.

In order to statistically test differences between both geographic regions, we computed Fisher's exact test for each protist genus and Symbiodinium clade (Figure 5). We found that coccidians and Symbiodinium clade D and A were linked to Djibouti, whereas Licnophora and Symbiodinium clade C were mostly associated with New Caledonia.

\section{DISCUSSION}

\section{Efficiency of Blocking Primers}

First, a very high specificity was obtained in silico for both blocking primers. In accordance with sequence entropy values (Supplementary Figure 1), all Scleractinia from the Silva database were expected to be blocked for 18SV1V2, and we found that $\sim 94 \%$ of them were targeted by the blocking primers of $18 \mathrm{SV} 4$. Although both blocking primers matched with 
Pocillopora sequences, we observed various efficiencies for the different samples from Djibouti and New Caledonia. On average Pocillopora still represented 70\% (from 30 to 92\%) and 39\% (from 7 to $66 \%$ ) of sequences for $18 \mathrm{SV} 1 \mathrm{~V} 2$ and $18 \mathrm{SV} 4$, respectively. Such variations were also described for artificial rDNA mixtures of algae and krill (between 26 and $42 \%$ of krill sequences were not blocked by blocking primers) (Vestheim and Jarman, 2008), and for gut content of fish (between 14 and $45 \%$ of sequences were not blocked by blocking primers) (Leray et al., 2013). These variations might be related to (i) the ratio between host and total sequences (Vestheim and Jarman, 2008), (ii) the ratio between blocking primers and targeted primer set concentrations (Vestheim and Jarman, 2008), and (iii) the complexity of samples for sequence composition, i.e., taxa diversity.

For environmental samples, the description of protist diversity might be improved by increasing the sequencing depth. In this exploratory study, we limited the number of sequences to an average of 60,000 per sample before the cleaning steps. One might also design blocking primers for Symbiodinium to increase the proportion of others protists. However, such an approach might fail if blocking primers for Symbiodinium and Scleractinia form primer dimers, and further if blocking primers for Symbiodinium target other closely related Suessiales or even alveolates. Indeed, other alveolates were previously identified in coral tissues (Moore et al., 2008).

\section{SV1V2 Is a More Suitable Marker Than 18SV4 to Explore Protist Diversity Within Corals}

Protist diversity was mostly described using $18 \mathrm{~S}$ rRNA and ITS2 markers in marine environments. While the $18 \mathrm{~S}$ rRNA gene was effective to study the diversity of a wide phylogenetic range of taxa within a sample (Viprey et al., 2008; Bik et al., 2012; de Vargas et al., 2015; Tragin et al., 2016), ITS were more appropriate for closely related taxa (Arif et al., 2014; Su et al., 2017). Because ITS polymorphism is high, it offers a higher resolution than the $18 \mathrm{~S}$ rRNA gene.

To date, ITS2 has been one of the most common markers used to describe Symbiodinium diversity (LaJeunesse et al., 2010; Wicks et al., 2010; Silverstein et al., 2011; Putnam et al., 2012; Tonk et al., 2013), because it provides enough resolution to describe Symbiodinium diversity within clades (LaJeunesse, 2002; Thornhill et al., 2017). In this study, we used two $18 \mathrm{~S}$ rRNA markers to describe phylogenetically distant taxa, but the comparison of phylogenetic signals for Symbiodinium showed that 18SV1V2 was more congruent with ITS2 than 18SV4. This difference might explain why we easily annotated all environmental Symbiodinium for 18SV1V2 compared to 18SV4. In addition, the diversity of protist genera was more even for 18SV1V2 than for 18SV4, as Symbiodinium and Licnophora represented a lower proportion of protists using 18SV1V2.

Overall, in comparison to 18SV4, blocking primers and the primer set for 18SV1V2 showed a better phylogenetic signal for Symbiodinium, and a more even representation of protist diversity. Based on our findings, we recommend the use of $18 \mathrm{SV} 1 \mathrm{~V} 2$ to study protists associated with coral colonies.

\section{Different Distributions Between Symbiodinium Clade $C$ and A/D}

Because of the advantages of 18SV1V2 and because we obtained sequences for protists other than Symbiodinium, we focused our analyses on this marker to study the distribution of protist genera and Symbiodinium clades within the different samples.

In order to describe Symbiodinium diversity, we looked for reference sequences of the different clades that matched with 18 SV1V2 and 18SV4. However, since ITS2 was the most common marker used so far, only representative sequences of clades A, B, C, D, and G were found. Unfortunately, although clade F was sometimes identified in Scleractinia (LaJeunesse, 2001; Rodriguez-Lanetty et al., 2003; Pochon et al., 2006), we were not able to use this clade to annotate environmental sequences. Clade $\mathrm{G}$ was described in other Anthozoa (Van Oppen et al., 2005; Bo et al., 2011), but not in scleractinian corals so far, thus it was not surprising that sequences of this clade were absent from our dataset. In contrast, clades A, C, D were the most common. In particular, clade $\mathrm{C}$ was dominant in New Caledonia, whereas clades D and A were mainly found in Djibouti. This result was similar to the analysis of the same samples using ITS2 (BrenerRaffalli et al., 2018). Thus, 18SV1V2 not only had a similar phylogenetic signal to ITS2, but also offered similar community composition for Symbiodinium.

\section{Coccidians and Licnophora Were the Two Other Main Taxa Within $P$. damicornis}

Although eukaryotic microborers were common in coral colonies (Tribollet, 2008b; Pica et al., 2016), we did not find any of them in our samples. However, even though boring microflora inhabited live and dead corals, they were more abundant in the latter ones (Le Campion-Alsumard et al., 1995; Tribollet and Payri, 2001; Tribollet, 2008a). Moreover, in this study we did not crush coral skeleton (i.e., where microborers inhabited), but instead, we extracted DNA from coral tissue. Similar to previous studies, we identified many Stramenopiles (KramarskyWinter et al., 2006; Harel et al., 2008; Siboni et al., 2010), and in particular different Bacillariophyta. Among them, the genus Navicula was present in one sample and was already isolated from the soft coral Dendronephthya (Hutagalung et al., 2014). We also found many fungi from the family Agaricomycetes (class Basidiomycota). Despite being a terrestrial mushroomforming fungi (Hibbett, 2007), this family was already identified in many marine samples, from deep-sea sediments to oxygendeficient environments, as well as within Acropora hyacinthus coral colonies (Amend et al., 2012). Many studies highlighted the presence of fungi in coral tissues: they were very diverse, and might be parasites, commensalists, and possibly mutualists that participated in nitrogen recycling (Wegley et al., 2007; Amend et al., 2012).

Furthermore, our samples contained many alveolates from divisions Dinophyta, Apicomplexa and Ciliophora. In particular, Licnophora (ciliates) and unidentified coccidia genera were the most common genera after Symbiodinium in P. damicornis colonies. Both ciliates and coccidians were already observed 
in coral samples using low-throughput methods, such as microscopy and culture, and they were mainly associated with coral diseases (Upton and Peters, 1986; Sweet and Bythell, 2012; Sweet et al., 2013; Sweet and Séré, 2016). However, the presence of Licnophora together with disease were possibly indirect, i.e., resulting from a microbiota dysbiosis, since they are known to feed others protozoa (Sweet and Séré, 2016). Moreover, coccidians were also found within healthy coral colonies of A. agaricita, A. tenuifolia, F. fragum, M. annularis, M. faveolata, M. ferox, P. astreoides, and S. siderea (Toller et al., 2002; Kirk et al., 2013; Šlapeta and Linares, 2013). In this study, corals did not show any outward signs of pathology, suggesting that these genera might be commensalists or mutualists. Interestingly, coccidian sequences of this study were very similar to the other coral-associated coccidians, and these sequences formed a robust monophyletic clade within Apicomplexa. This observation suggested that a speciation event of coccidians was linked to interactions with corals. Future studies should test the role of coccidians in coral holobionts. For example, it would be interesting to know whether these coccidians have retained a relict or a functional plastid like the coral-associated chromerids (Janouškovec et al., 2012).

Finally, Licnophora and coccidians had different distributions within our samples from Djibouti and New Caledonia. Similarly to Symbiodinium clades, geographic locations, Pocillopora clades and thermal regimes might influence their distribution. However, because of our sampling strategy, it was not possible to identify the factors responsible for this pattern.

To conclude, we designed two blocking primers to characterize protist diversity using high-throughput amplicon sequencing for the first time within coral colonies. We were able to characterize the diversity of Symbiodinium and of other less known genera associated with $P$. damicornis sensu lato. Among them, Licnophora and unidentified coccidia genera were common in coral samples from Djibouti and New Caledonia. In particular, coccidian sequences were phylogenetically related to coccidians described in other scleractinian coral species. Furthermore, different distributions were highlighted between Licnophora and coccidians, and between Symbiodinium clades $\mathrm{C}$ and $\mathrm{A} / \mathrm{D}$. Because the dataset was limited to two geographic regions, we did not know the respective influence of geography, $P$. damicornis clades or thermal regimes on protist assemblages. Moreover, we could not confirm that Licnophora and coccidians were part of the coral holobiont, and not simply just a part of

\section{REFERENCES}

Adjeroud, M., Guérécheau, A., Vidal-Dupiol, J., Flot, J.-F., Arnaud-Haond, S., and Bonhomme, F. (2014). Genetic diversity, clonality and connectivity in the scleractinian coral Pocillopora damicornis: a multi-scale analysis in an insular, fragmented reef system. Mar. Biol. 161, 531-541. doi: 10.1007/s00227-0132355-9

Ainsworth, T. D., Fordyce, A. J., and Camp, E. F. (2017). The other microeukaryotes of the coral reef microbiome. Trends Microbiol. 25, 980-991. doi: 10.1016/j.tim.2017.06.007

Ainsworth, T. D., Krause, L., Bridge, T., Torda, G., Raina, J.-B., Zakrzewski, M., et al. (2015). The coral core microbiome identifies rare bacterial taxa as ubiquitous endosymbionts. ISME J. 9, 2261-2274. doi: 10.1038/ismej.2015.39 the larger environmental microbial community. Notably, future studies should decipher if they serve a specific function within the holobiont. However, we believe that these blocking primers are promising tools to bring new knowledge and understanding of the diversity and distribution of protists within $P$. damicornis colonies, as well as for other species of corals, as they were designed to target most Scleractinia.

\section{AUTHOR CONTRIBUTIONS}

$\mathrm{CC}, \mathrm{J}-\mathrm{ME}$, and ET conceived the project. SB and PL designed the experimental protocol to test blocking primers. JV-D and MA were involved in the collection of samples and data acquisition. CC, LG, and ET performed the analyses. CC drafted the manuscript. All authors contributed to critical revisions and approved the final manuscript.

\section{FUNDING}

CC benefited of post-doctoral fellowships from CNRS and IFREMER. This work was supported by the French National Research Agency ANR, project ANR-14-CE19-0023 DECIPHER (coordinator G. Mitta), Campus France PHC Hubert Curien program Maïmonide-Israel, and by the DHOF program of the UMR5244/IHPE (http://ihpe.univ-perp.fr/en/ihpe-transversalholobiont/).

\section{ACKNOWLEDGMENTS}

We thank Lorenzo Bramanti for help in collecting corals from Djibouti, and IHPE members for stimulating discussions. We are grateful to the genotoul bioinformatics platform Toulouse MidiPyrenees and Sigenae group for providing help and computing resources thanks to Galaxy instance http://sigenae-workbench. toulouse.inra.fr.

\section{SUPPLEMENTARY MATERIAL}

The Supplementary Material for this article can be found online at: https://www.frontiersin.org/articles/10.3389/fmicb. 2018.02043/full\#supplementary-material

Amend, A. S., Barshis, D. J., and Oliver, T. A. (2012). Coral-associated marine fungi form novel lineages and heterogeneous assemblages. ISME J. 6, 1291-1301. doi: 10.1038/ismej.2011.193

Arif, C., Daniels, C., Bayer, T., Banguera-Hinestroza, E., Barbrook, A., Howe, C. J., et al. (2014). Assessing Symbiodinium diversity in scleractinian corals via nextgeneration sequencing-based genotyping of the ITS2 rDNA region. Mol. Ecol. 23, 4418-4433. doi: 10.1111/mec.12869

Bayer, T., Neave, M. J., Alsheikh-Hussain, A., Aranda, M., Yum, L. K., Mincer, T., et al. (2013). The microbiome of the Red Sea coral Stylophora pistillata is dominated by tissue-associated Endozoicomonas bacteria. Appl. Environ. Microbiol. 79, 4759-4762. doi: 10.1128/AEM.00695-13

Bik, H. M., Sung, W., De Ley, P., Baldwin, J. G., Sharma, J., Rocha-Olivares, A., et al. (2012). Metagenetic community analysis of microbial eukaryotes illuminates 
biogeographic patterns in deep-sea and shallow water sediments. Mol. Ecol. 21, 1048-1059. doi: 10.1111/j.1365-294X.2011.05297.x

Bo, M., Baker, A., Gaino, E., Wirshing, H., Scoccia, F., and Bavestrello, G. (2011). First description of algal mutualistic endosymbiosis in a black coral (Anthozoa: Antipatharia). Mar. Ecol. Prog. Ser. 435, 1-11. doi: 10.3354/meps09228

Brener-Raffalli, K., Clerissi, C., Vidal-Dupiol, J., Adjeroud, M., Bonhomme, F., Pratlong, M., et al. (2018). Thermal regime and host clade, rather than geography, drive Symbiodinium and bacterial assemblages in the scleractinian coral Pocillopora damicornis sensu lato. Microbiome 6:39. doi: 10.1186/s40168018-0423-6

Coffroth, M. A., and Santos, S. R. (2005). Genetic diversity of symbiotic dinoflagellates in the genus Symbiodinium. Protist 156, 19-34. doi: 10.1016/j. protis.2005.02.004

de Vargas, C., Audic, S., Henry, N., Decelle, J., Mahé, F., Logares, R., et al. (2015). Eukaryotic plankton diversity in the sunlit ocean. Science 348:1261605. doi: $10.1126 /$ science. 1261605

Edgar, R. C. (2004). MUSCLE: multiple sequence alignment with high accuracy and high throughput. Nucleic Acids Res. 32, 1792-1797. doi: 10.1093/nar/gkh340

Escudié, F., Auer, L., Bernard, M., Mariadassou, M., Cauquil, L., Vidal, K., et al. (2017). FROGS: find, rapidly, OTUs with galaxy solution. Bioinformatics 34, 1287-1294. doi: 10.1093/bioinformatics/btx791

Guillou, L., Bachar, D., Audic, S., Bass, D., Berney, C., Bittner, L., et al. (2012). The protist ribosomal reference database (PR2): a catalog of unicellular eukaryote Small Sub-Unit rRNA sequences with curated taxonomy. Nucleic Acids Res. 41, D597-D604. doi: 10.1093/nar/gks1160

Harel, M., Ben-Dov, E., Rasoulouniriana, D., Siboni, N., Kramarsky-Winter, E., Loya, Y., et al. (2008). A new Thraustochytrid, strain Fng1, isolated from the surface mucus of the hermatypic coral Fungia granulosa. FEMS Microbiol. Ecol. 64, 378-387. doi: 10.1111/j.1574-6941.2008.00464.x

Hibbett, D. S. (2007). After the gold rush, or before the flood? Evolutionary morphology of mushroom-forming fungi (Agaricomycetes) in the early 21st century. Mycol. Res. 111, 1001-1018. doi: 10.1016/j.mycres.2007.01.012

Hutagalung, R. A., Sukoco, A. E., Soedharma, D., Goreti, L. M., Andrean, I., Elshaddai, B., et al. (2014). Isolation, identification and growth optimization of microalgae derived from soft coral Dendronephthya sp. APCBEE Proc. 10, 305-310. doi: 10.1016/j.apcbee.2014.10.057

Janouškovec, J., Horák, A., Barott, K. L., Rohwer, F. L., and Keeling, P. J. (2012). Global analysis of plastid diversity reveals apicomplexan-related lineages in coral reefs. Curr. Biol. 22, R518-R519. doi: 10.1016/j.cub.2012.04.047

Katoh, K., Misawa, K., Kuma, K., and Miyata, T. (2002). MAFFT: a novel method for rapid multiple sequence alignment based on fast Fourier transform. Nucleic Acids Res. 30, 3059-3066. doi: 10.1093/nar/gkf436

Kirk, N. L., Thornhill, D. J., Kemp, D. W., Fitt, W. K., and Santos, S. R. (2013). Ubiquitous associations and a peak fall prevalence between apicomplexan symbionts and reef corals in Florida and the Bahamas. Coral Reefs 32, 847-858. doi: 10.1007/s00338-013-1038-9

Kramarsky-Winter, E., Harel, M., Siboni, N., Dov, E. B., Brickner, I., Loya, Y., et al. (2006). Identification of a protist-coral association and its possible ecological role. Mar. Ecol. Prog. Ser. 317, 67-73. doi: 10.3354/meps317067

LaJeunesse, T. C. (2001). Investigating the biodiversity, ecology, and phylogeny of endosymbiotic dinoflagellates in the genus Symbiodinium using the ITS region: in search of a "species" level marker. J. Phycol. 37, 866-880. doi: 10.1046/j.15298817.2001.01031.x

LaJeunesse, T. C. (2002). Diversity and community structure of symbiotic dinoflagellates from Caribbean coral reefs. Mar. Biol. 141, 387-400. doi: 10. 1007/s00227-002-0829-2

LaJeunesse, T. C., Pettay, D. T., Sampayo, E. M., Phongsuwan, N., Brown, B., Obura, D. O., et al. (2010). Long-standing environmental conditions, geographic isolation and host-symbiont specificity influence the relative ecological dominance and genetic diversification of coral endosymbionts in the genus Symbiodinium. J. Biogeogr. 37, 785-800. doi: 10.1111/j.1365-2699.2010. 02273.x

Le Campion-Alsumard, T., Golubic, S., and Hutchings, P. (1995). Microbial endoliths in skeletons of live and dead corals: Porites lobata (Moorea, French Polynesia). Mar. Ecol. Prog. Ser. 117, 149-157. doi: 10.3354/meps117149

Leray, M., Agudelo, N., Mills, S. C., and Meyer, C. P. (2013). Effectiveness of annealing blocking primers versus restriction enzymes for characterization of generalist diets: unexpected prey revealed in the gut contents of two coral reef fish species. PLoS One 8:e58076. doi: 10.1371/journal.pone.0058076

Magoc, T., and Salzberg, S. L. (2011). FLASH: fast length adjustment of short reads to improve genome assemblies. Bioinformatics 27, 2957-2963. doi: 10.1093/ bioinformatics/btr507

Mahé, F., Rognes, T., Quince, C., de Vargas, C., and Dunthorn, M. (2015). Swarm v2: highly-scalable and high-resolution amplicon clustering. PeerJ 3:e1420. doi: $10.7717 /$ peerj. 1420

Mantel, N. (1967). The detection of disease clustering and a generalized regression approach. Cancer Res. 27, 209.

Martin, M. (2011). Cutadapt removes adapter sequences from high-throughput sequencing reads. EMBnet J. 17:10. doi: 10.14806/ej.17.1.200

McDevitt-Irwin, J. M., Baum, J. K., Garren, M., and Vega Thurber, R. L. (2017). Responses of coral-associated bacterial communities to local and global stressors. Front. Mar. Sci. 4:262. doi: 10.3389/fmars.2017.00262

McMurdie, P. J., and Holmes, S. (2013). phyloseq: an R package for reproducible interactive analysis and graphics of microbiome census data. PLoS One 8:e61217. doi: 10.1371/journal.pone.0061217

Minh, B. Q., Nguyen, M. A. T., and von Haeseler, A. (2013). Ultrafast approximation for phylogenetic bootstrap. Mol. Biol. Evol. 30, 1188-1195. doi: $10.1093 / \mathrm{molbev} / \mathrm{mst} 024$

Mohamed, A. R., Cumbo, V. R., Harii, S., Shinzato, C., Chan, C. X., Ragan, M. A., et al. (2018). Deciphering the nature of the coral-Chromera association. ISME J. 12, 776-790. doi: 10.1038/s41396-017-0005-9

Moore, R. B., Oborník, M., Janouškovec, J., Chrudimský, T., Vancová, M., Green, D. H., et al. (2008). A photosynthetic alveolate closely related to apicomplexan parasites. Nature 451, 959-963. doi: 10.1038/nature06635

Neave, M. J., Apprill, A., Ferrier-Pagès, C., and Voolstra, C. R. (2016). Diversity and function of prevalent symbiotic marine bacteria in the genus Endozoicomonas. Appl. Microbiol. Biotechnol. 100, 8315-8324. doi: 10.1007/s00253-016-7777-0

Neave, M. J., Rachmawati, R., Xun, L., Michell, C. T., Bourne, D. G., Apprill, A., et al. (2017). Differential specificity between closely related corals and abundant Endozoicomonas endosymbionts across global scales. ISME J. 11, 186-200. doi: 10.1038 /ismej.2016.95

Nguyen, L.-T., Schmidt, H. A., von Haeseler, A., and Minh, B. Q. (2015). IQ-TREE: a fast and effective stochastic algorithm for estimating maximum-likelihood phylogenies. Mol. Biol. Evol. 32, 268-274. doi: 10.1093/molbev/msu300

Peixoto, R. S., Rosado, P. M., Leite, D. C., Rosado, A. S., and Bourne, D. G. (2017). Beneficial microorganisms for corals (BMC): proposed mechanisms for coral health and resilience. Front. Microbiol. 8:341. doi: 10.3389/fmicb.2017.00341

Pica, D., Tribollet, A., Golubic, S., Bo, M., Di Camillo, C. G., Bavestrello, G., et al. (2016). Microboring organisms in living stylasterid corals (Cnidaria. Hydrozoa). Mar. Biol. Res. 12, 573-582. doi: 10.1080/17451000.2016.1169298

Pochon, X., Montoya-Burgos, J. I., Stadelmann, B., and Pawlowski, J. (2006). Molecular phylogeny, evolutionary rates, and divergence timing of the symbiotic dinoflagellate genus Symbiodinium. Mol. Phylogenet. Evol. 38, 20-30. doi: 10.1016/j.ympev.2005.04.028

Price, M. N., Dehal, P. S., and Arkin, A. P. (2010). FastTree 2-approximately maximum-likelihood trees for large alignments. PLoS One 5:e9490. doi: 10. 1371/journal.pone.0009490

Putnam, H. M., Stat, M., Pochon, X., and Gates, R. D. (2012). Endosymbiotic flexibility associates with environmental sensitivity in scleractinian corals. Proc. R. Soc. B Biol. Sci. 279, 4352-4361. doi: 10.1098/rspb.2012.1454

Quast, C., Pruesse, E., Yilmaz, P., Gerken, J., Schweer, T., Yarza, P., et al. (2013). The SILVA ribosomal RNA gene database project: improved data processing and web-based tools. Nucleic Acids Res. 41, D590-D596. doi: 10.1093/nar/ gks1219

Quigley, K. M., Davies, S. W., Kenkel, C. D., Willis, B. L., Matz, M. V., and Bay, L. K. (2014). Deep-sequencing method for quantifying background abundances of Symbiodinium types: exploring the rare Symbiodinium biosphere in reefbuilding corals. PLoS One 9:e94297. doi: 10.1371/journal.pone.0094297

R Core Team (2018). R: A Language and Environment for Statistical Computing. Vienna: R Foundation for Statistical Computing. available at: http://www.Rproject.org

Ramette, A., and Buttigieg, P. L. (2014). The R package otu2ot for implementing the entropy decomposition of nucleotide variation in sequence data. Front. Microbiol. 5:601. doi: 10.3389/fmicb.2014.00601 
Ritchie, K. B. (2006). Regulation of microbial populations by coral surface mucus and mucus-associated bacteria. Mar. Ecol. Prog. Ser. 322, 1-14. doi: 10.3354/ meps 322001

Rodriguez-Lanetty, M., Chang, S.-J., and Song, J.-I. (2003). Specificity of two temperate dinoflagellate-anthozoan associations from the north-western Pacific Ocean. Mar. Biol. 143, 1193-1199. doi: 10.1007/s00227-003-1165-x

Rognes, T., Flouri, T., Nichols, B., Quince, C., and Mahé, F. (2016). VSEARCH: a versatile open source tool for metagenomics. PeerJ 4:e2584. doi: 10.7717/peerj. 2584

Rohwer, F., Seguritan, V., Azam, F., and Knowlton, N. (2002). Diversity and distribution of coral-associated bacteria. Mar. Ecol. Prog. Ser. 243, 1-10. doi: 10.3354/meps 243001

Schloss, P. D., Westcott, S. L., Ryabin, T., Hall, J. R., Hartmann, M., Hollister, E. B., et al. (2009). Introducing mothur: open-source, platform-independent, community-supported software for describing and comparing microbial communities. Appl. Environ. Microbiol. 75, 7537-7541. doi: 10.1128/AEM. 01541-09

Schrével, J., Valigurová, A., Prensier, G., Chambouvet, A., Florent, I., and Guillou, L. (2016). Ultrastructure of Selenidium pendula, the type species of archigregarines, and phylogenetic relations to other marine Apicomplexa. Protist 167, 339-368. doi: 10.1016/j.protis.2016.06.001

Shnit-Orland, M., and Kushmaro, A. (2009). Coral mucus-associated bacteria: a possible first line of defense. FEMS Microbiol. Ecol. 67, 371-380. doi: 10.1111/j. 1574-6941.2008.00644.x

Siboni, N., Rasoulouniriana, D., Ben-Dov, E., Kramarsky-Winter, E., Sivan, A., Loya, Y., et al. (2010). Stramenopile microorganisms associated with the massive coral Favia sp. J. Eukaryot. Microbiol. 57, 236-244. doi: 10.1111/j.15507408.2010.00469.x

Silverstein, R., Correa, A., LaJeunesse, T., and Baker, A. (2011). Novel algal symbiont (Symbiodinium spp.) diversity in reef corals of Western Australia. Mar. Ecol. Prog. Ser. 422, 63-75. doi: 10.3354/meps08934

Šlapeta, J., and Linares, M. C. (2013). Combined amplicon pyrosequencing assays reveal presence of the Apicomplexan "type-N" (cf. Gemmocystis cylindrus) and Chromera velia on the great Barrier Reef, Australia. PLoS One 8:e76095. doi: 10.1371/journal.pone.0076095

Stoeck, T., Bass, D., Nebel, M., Christen, R., Jones, M. D., Breiner, H. W., et al. (2010). Multiple marker parallel tag environmental DNA sequencing reveals a highly complex eukaryotic community in marine anoxic water. Mol. Ecol. 19, 21-31. doi: 10.1111/j.1365-294X.2009.04480.x

Su, L., Zhang, Q., and Gong, J. (2017). Development and evaluation of specific PCR primers targeting the ribosomal DNA-internal transcribed spacer (ITS) region of peritrich ciliates in environmental samples. Chin. J. Oceanol. Limnol. 36, 818-826. doi: 10.1007/s00343-018-6326-3

Sweet, M., and Bythell, J. (2012). Ciliate and bacterial communities associated with White syndrome and brown band disease in reef-building corals. Environ. Microbiol. 14, 2184-2199. doi: 10.1111/j.1462-2920.2012.02746.x

Sweet, M. J., Craggs, J., Robson, J., and Bythell, J. C. (2013). Assessment of the microbial communities associated with white syndrome and brown jelly syndrome in aquarium corals. J. Zoo Aquar. Res. 1, 20-27.

Sweet, M. J., and Séré, M. G. (2016). Ciliate communities consistently associated with coral diseases. J. Sea Res. 113, 119-131. doi: 10.1016/j.seares.2015.06.008

Tan, S., and Liu, H. (2018). Unravel the hidden protistan diversity: application of blocking primers to suppress PCR amplification of metazoan DNA. Appl. Microbiol. Biotechnol. 102, 389-401. doi: 10.1007/s00253-017-8565-1

Theis, K. R., Dheilly, N. M., Klassen, J. L., Brucker, R. M., Baines, J. F., Bosch, T. C. G., et al. (2016). Getting the hologenome concept right: an ecoevolutionary framework for hosts and their microbiomes. mSystems 1:e28-16. doi: 10.1128/mSystems.00028-16

Thingstad, T. F., Bellerby, R. G. J., Bratbak, G., Børsheim, K. Y., Egge, J. K., Heldal, M., et al. (2008). Counterintuitive carbon-to-nutrient coupling in an Arctic pelagic ecosystem. Nature 455, 387-390. doi: 10.1038/nature07235

Thornhill, D. J., Howells, E. J., Wham, D. C., Steury, T. D., and Santos, S. R. (2017). Population genetics of reef coral endosymbionts (Symbiodinium, Dinophyceae). Mol. Ecol. 26, 2640-2659. doi: 10.1111/mec.14055

Thurber, R. V., Payet, J. P., Thurber, A. R., and Correa, A. M. S. (2017). Virus-host interactions and their roles in coral reef health and disease. Nat. Rev. Microbiol. 15, 205-2016. doi: 10.1038/nrmicro.2016.176

Toller, W., Rowan, R., and Knowlton, N. (2002). Genetic evidence for a protozoan (phylum Apicomplexa) associated with corals of the Montastraea annularis species complex. Coral Reefs 21, $143-146$.

Tonk, L., Bongaerts, P., Sampayo, E. M., and Hoegh-Guldberg, O. (2013). SymbioGBR: a web-based database of Symbiodinium associated with cnidarian hosts on the Great Barrier Reef. BMC Ecol. 13:7. doi: 10.1186/1472-6785-13-7

Tragin, M., Lopes, dos Santos, A., Christen, R., and Vaulot, D. (2016). Diversity and ecology of green microalgae in marine systems: an overview based on $18 \mathrm{~S}$ rRNA gene sequences. Perspect. Phycol. 3, 141-154. doi: 10.1127/pip/2016/0059

Tribollet, A. (2008a). Dissolution of dead corals by euendolithic microorganisms across the Northern Great Barrier Reef (Australia). Microb. Ecol. 55, 569-580. doi: 10.1007/s00248-007-9302-6

Tribollet, A. (2008b). "The boring microflora in modern coral reef ecosystems: a review of its roles," in Current Developments in Bioerosion Erlangen Earth Conference Series, eds M. Wisshak and L. Tapanila (Berlin: Springer), 67-94.

Tribollet, A., and Payri, C. (2001). Bioerosion of the coralline alga hydrolithon onkodes by microborers in the coral reefs of Moorea, French polynesia. Oceanol. Acta 24, 329-342. doi: 10.1016/S0399-1784(01)01150-1

Upton, S. J., and Peters, E. C. (1986). A new and unusual species of coccidium (Apicomplexa: Agamococcidiorida) from Caribbean scleractinian corals. J. Invertebr. Pathol. 47, 184-193. doi: 10.1016/0022-2011(86)90045-5

Van Oppen, M. J. H., Mieog, J. C., Sanchez, C. A., and Fabricius, K. E. (2005). Diversity of algal endosymbionts (zooxanthellae) in octocorals: the roles of geography and host relationships. Mol. Ecol. 14, 2403-2417. doi: 10.1111/j. 1365-294X.2005.02545.x

Vestheim, H., and Jarman, S. N. (2008). Blocking primers to enhance PCR amplification of rare sequences in mixed samples - A case study on prey DNA in Antarctic krill stomachs. Front. Zool. 5:12. doi: 10.1186/1742-9994-5-12

Viprey, M., Guillou, L., Ferréol, M., and Vaulot, D. (2008). Wide genetic diversity of picoplanktonic green algae (Chloroplastida) in the Mediterranean Sea uncovered by a phylum-biased PCR approach. Environ. Microbiol. 10, 18041822. doi: 10.1111/j.1462-2920.2008.01602.x

Wegley, L., Edwards, R., Rodriguez-Brito, B., Liu, H., and Rohwer, F. (2007). Metagenomic analysis of the microbial community associated with the coral Porites astreoides. Environ. Microbiol. 9, 2707-2719. doi: 10.1111/j.1462-2920. 2007.01383.x

Wegley, L., Yu, Y., Breitbart, M., Casas, V., Kline, D. I., and Rohwer, F. (2004). Coral-associated archaea. Mar. Ecol. Prog. Ser. 273, 89-96. doi: 10.3354/ meps 273089

Wicks, L. C., Sampayo, E., Gardner, J. P. A., and Davy, S. K. (2010). Local endemicity and high diversity characterise high-latitude coral-Symbiodinium partnerships. Coral Reefs 29, 989-1003. doi: 10.1007/s00338-010-0649-7

Winnepenninckx, B., Backeljau, T., and Wachter, R. (1993). Extraction of high molecular weight DNA from molluscs. Trends Genet. 9:407. doi: 10.1016/01689525(93)90102-N

Wuyts, J., De Rijk, P., Van de Peer, Y., Pison, G., Rousseeuw, P., and De Wachter, R. (2000). Comparative analysis of more than 3000 sequences reveals the existence of two pseudoknots in area V4 of eukaryotic small subunit ribosomal RNA. Nucleic Acids Res. 28, 4698-4708. doi: 10.1093/nar/28.23.4698

Wuyts, J., Van de Peer, Y., Winkelmans, T., and De Wachter, R. (2002). The European database on small subunit ribosomal RNA. Nucleic Acids Res. 30, 183-185. doi: 10.1093/nar/30.1.183

Yilmaz, P., Parfrey, L. W., Yarza, P., Gerken, J., Pruesse, E., Quast, C., et al. (2014). The SILVA and "All-species Living Tree Project (LTP)" taxonomic frameworks. Nucleic Acids Res. 42, D643-D648. doi: 10.1093/nar/gkt1209

Ziegler, M., Seneca, F. O., Yum, L. K., Palumbi, S. R., and Voolstra, C. R. (2017). Bacterial community dynamics are linked to patterns of coral heat tolerance. Nat. Commun. 8:14213. doi: 10.1038/ncomms 14213

Conflict of Interest Statement: The authors declare that the research was conducted in the absence of any commercial or financial relationships that could be construed as a potential conflict of interest.

Copyright (c) 2018 Clerissi, Brunet, Vidal-Dupiol, Adjeroud, Lepage, Guillou, Escoubas and Toulza. This is an open-access article distributed under the terms of the Creative Commons Attribution License (CC BY). The use, distribution or reproduction in other forums is permitted, provided the original author $(s)$ and the copyright owner(s) are credited and that the original publication in this journal is cited, in accordance with accepted academic practice. No use, distribution or reproduction is permitted which does not comply with these terms. 